\title{
Kinetic Study of Selective Chlorination of Iron in Ilmenite Ore
}

\section{So-Yeong Lee1, Sung-Hun Park1, Ho-Sang Sohn1 School of materials science and engineering, Kyungpook National University, Daegu, Korea}

\author{
Key words: Ilmenite, Selective chlorination, Synthetic rutile, Shrinking core model
}

\begin{abstract}
$\underline{\text { Abstract }}$
The selective chlorination of ilmenite with coke and chlorine gas was conducted in the fixed bed reactor and effects of coke content and reaction temperature on reaction rate were investigated. In particular, the chlorination rate of iron in ilmenite was simulated by the unreacted shrinking core model. The reaction rate was simulated by calculating the chlorine gas consumption rate as the unreacted core shrinks. In addition, each of reaction resistances that chemical reaction at the reaction interface, diffusion through the product layer, and boundary film mass transfer resistances were calculated. The simulated reaction rates were in good agreement with the experimental results and the rate controlling step changed as the chlorination reaction progressed. Furthermore, the diffusion resistance through the product layer was dominant at lower reaction temperature, whereas the chemical reaction was dominant as the reaction temperature increased. It is because the diffusion of chlorine gas through the product layer could be hindered at lower reaction temperatures.
\end{abstract}

\section{$\underline{\text { Introduction }}$}

In recent years, as the demand for titanium used in national defense, aerospace, and biometric industries increases, it is necessary to use lowgrade titanium ores such as abundant and inexpensive ilmenite. However, it is difficult to directly use the low-grade titanium ore to the direct chlorination process because it contains a large amount of impurities such as iron which generate the iron chloride during the chlorination process. Therefore, the consumption efficiency of chlorine gas and the purity of TiCl4 can be improved by adding synthetic rutile with relatively high $\mathrm{TiO} 2$ content through the process of upgrading the ilmenite ore. Although a lot of studies on this selective chlorination method of ilmenite have been reported, there is a limit to clearly identify the rate-controlling step[1-5]. In this study, the reaction kinetics was analyzed by applying the unreacted nuclear model, and the variation in rate-controlling step on the selective chlorination of Fe in ilmenite ore through the addition of chlorine gas and coke was investigated.

\section{Materials and experimental process}

The ilmenite concentrates used in the present work were analyzed by inductively coupled plasma optical emission spectrometer(ICP-OES), and the results are listed in Table 1. Coke ( $98 \%$ fixed carbon) was used as a reducing agent. The particle size distribution of ilmenite and coke used in the experiments were determined as $180 \mu \mathrm{m} \sim 212 \mu \mathrm{m}$, and $350 \mu \mathrm{m} \sim 600 \mu \mathrm{m}$, respectively.

Table 1. Chemical compositions of ilmenite used in this study

\begin{tabular}{c|ccccccccc}
\hline \multicolumn{10}{c}{ Concentration of components (wt.\%) } \\
\hline & $\mathrm{Ti}$ & $\mathrm{Fe}$ & $\mathrm{Si}$ & $\mathrm{Mn}$ & $\mathrm{Al}$ & $\mathrm{Mg}$ & $\mathrm{Cr}$ & $\mathrm{Ca}$ & $\mathrm{V}$ \\
\hline Ilmenite & 32.15 & 26.99 & 1.15 & 0.99 & 0.77 & 0.50 & 0.42 & 0.20 & 0.12 \\
\hline
\end{tabular}

A schematic diagram of experimental apparatus for the chlorination of ilmenite is illustrated in Figure 1. A quartz tube (I.D. 55 mm) was placed in the horizontal furnace. Approximately $10.0 \mathrm{~g}$ of ilmenite concentrate and coke were mixed and were placed in the quartz boat. The sample boat was introduced to the furnace, which already heated to the specific temperature. Batch experiments were conducted under different reaction temperature between $1023 \mathrm{~K}$ and $1173 \mathrm{~K}$ for 5, 10, 20, 30, 40, $60 \mathrm{~min}$. During the chlorination reaction, the chlorine gas $(99.99 \%)$ flow rate was controlled by the mass flow controller. And excess chlorine gas and produced metal chloride gases were absorbed by sodium hydroxide aqueous solution. The reacted sample was washed with dilute hydrochloric acid and then dried. Samples were sieved to separate the synthetic rutile and coke, and it was analyzed by the ICP, SEM and the mercury porosimetry. 


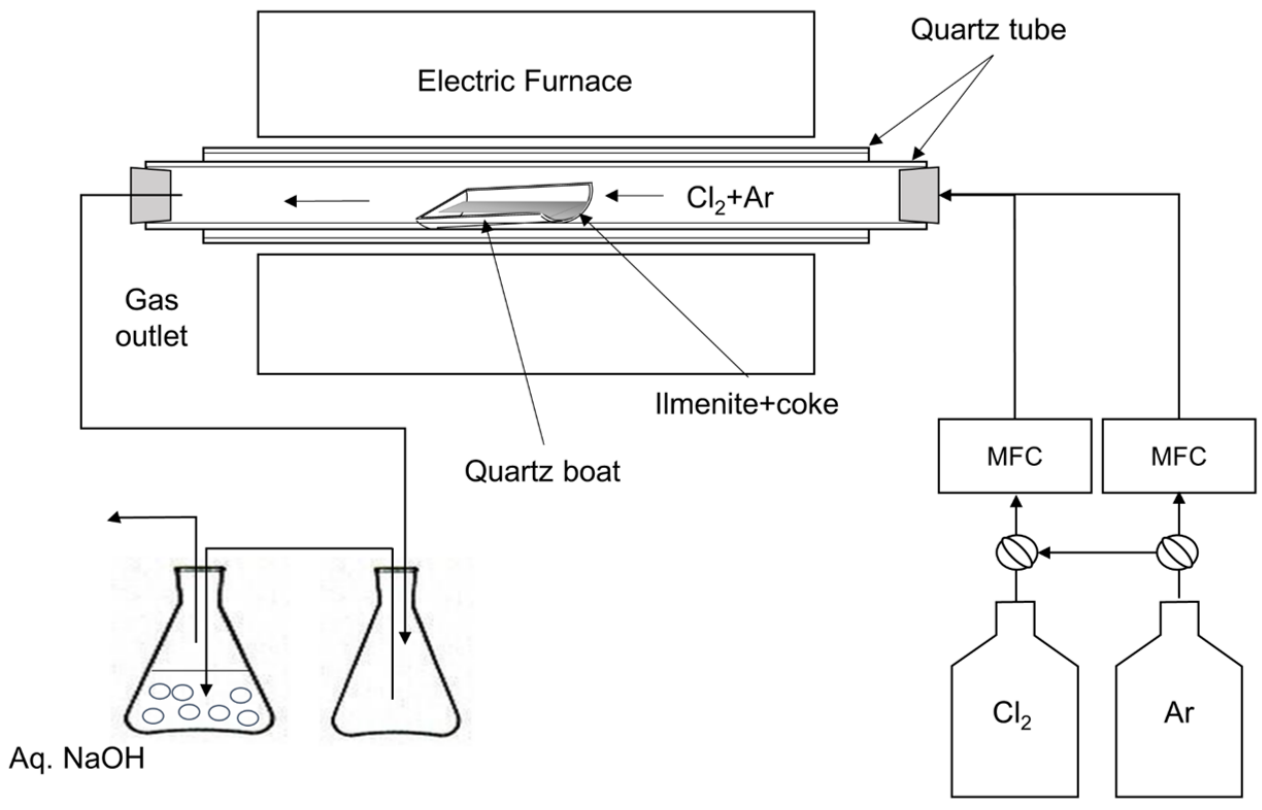

Figure 1. Experimental apparatus for the selective chlorination of ilmenite.

\section{Results and Discussion}

As described above, iron oxide in the ilmenite particle was preferentially removed by the selective chlorination reaction. The particle cross section of reaction products are shown in Figure 2. From the SEM image, the porous product layer of rutile(TiO2) surrounded the unreacted core. The chlorine gas would pass through the pores and then it reach reaction surface. As the reaction proceeded, the unreacted core would shrink, and finally the selective chlorination reaction completed. 

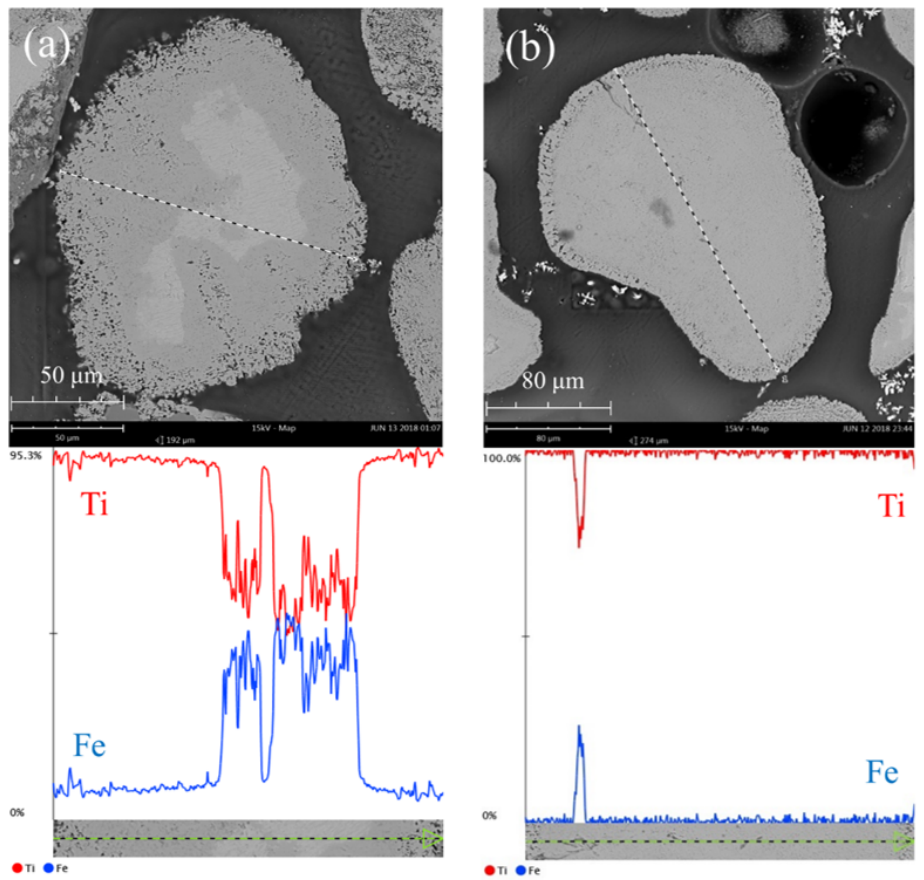

Figure 2. Cross section of reaction products chlorinated at $1123 \mathrm{~K}$, coke $3 \mathrm{~g}, \mathrm{pCl} 2=1$ for (a) $30 \mathrm{~min}$, and (b) $60 \mathrm{~min}$.

In this study, the shrinking core model proposed by Yagi[6] was applied to simulate the selective chlorination of iron in the ilmenite ore. The shrinking core model classifies the gas-solid reaction procedure and the rates of each stages were presented as follows:

1) Mass transfer of reactant gas through gas boundary layer

$J_{C_{2}}=\frac{4 \pi r_{0}^{2} k_{g}}{\mathrm{R} T}\left(p^{b}-p^{s}\right)$

2) Diffusion through the product layer formed on the particle surface

$J_{C_{2}}=\frac{4 \pi r r_{i} D_{t e f}}{\left(r_{0}-r_{i}\right) \mathrm{R} T}\left(p^{s}-p^{i}\right)$

3) Chemical reaction at the reaction interface

$J_{\mathrm{Cl}_{2}}=\frac{4 \pi r_{i}^{2} k_{r}}{\mathrm{R} T} p^{i}$

Thus, from equation (1) (3), the overall rate of selective chlorination reaction of ilmenite particle is expressed as

$J_{\mathrm{Cl}_{2}}=\frac{4 \pi r_{o}^{2} p^{b} / \mathrm{R} T}{\frac{1}{k_{g}}+\frac{r_{o}}{r_{i}} \frac{\left(r_{s}-r_{i}\right)}{D_{\epsilon f f}}+\left(\frac{r_{o}}{r_{i}}\right)^{2} \frac{1}{k_{r}}}$

The rate of the chlorination of iron can be expressed in terms of the decreasing reaction interface radius with time and the equivalent amount of chlorine gas that has reacted, i.e.

$\frac{d r_{i}}{d t}=-\frac{M_{p}}{4 \pi r_{i}^{2} \rho_{p}} \cdot J_{\mathrm{Cl}_{2}}$

The radius $r i$ would be a function of time and reaction rate $\mathrm{x}$ for those cases where there is shrinkage of core radius. 
$x=1-\left(\frac{r_{i}}{r_{0}}\right)^{3}$

(6)

The calculated chlorination reaction rate was compared with the experimental results in Figure 3. The simulated curves were in good agreement with observed reaction rates obtained in the experimental results. It means that the present reaction model reasonably explains the selective chlorination rates of ilmenite.

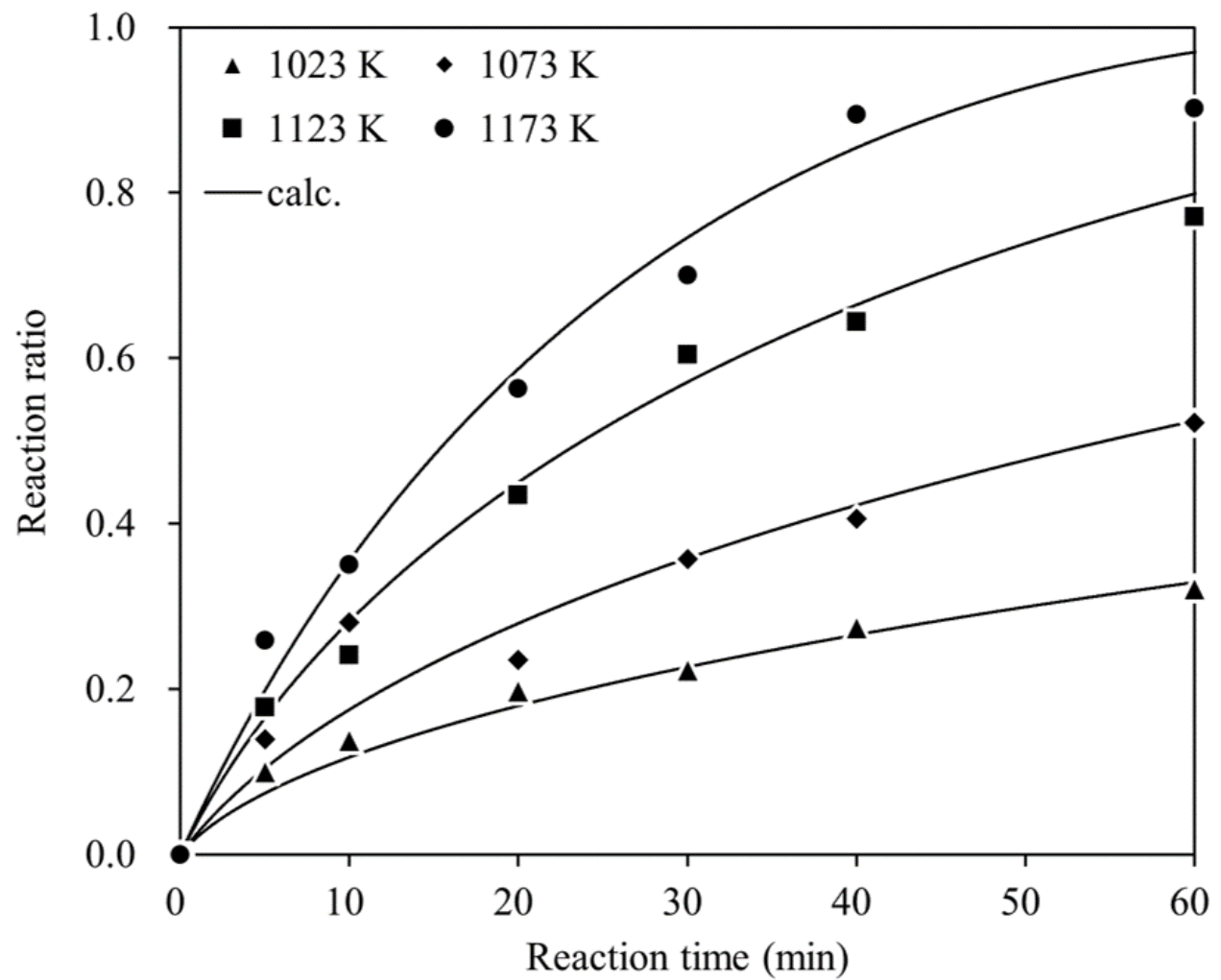

Figure 3. Comparison of experimental results and calculated reaction ratio during the chlorination reaction of ilmenite (coke $1 \mathrm{~g}$, $\mathbf{Q}=\mathbf{1 0} \mathbf{c m} 3 / \mathbf{s}$, and $\left.p C l 2_{=1} \mathbf{~ a t m}\right)$.

In order to determine the rate controlling step of the selective chlorination reaction, the resistance factors hindering the reaction were calculated and the resistances of each reaction steps could be represented as the corresponding denominator term in equation (4). Figure 4 shows the calculated reaction resistances of mass transfer through gas film boundary, $\eta \mathrm{g}$, chemical reaction, $\eta \mathrm{r}$, and the chlorine gas diffusion through product layer $\eta d$. The effect of gas film mass transfer on the conversion-time relationship was negligible and the rate controlling step turn from chemical reaction controls into gas diffusion controls. Generally, the structural changes, such as the growth of porous product layer, and a shrinkage of unreacted core occur in a particle. These transformation accounts for the change of rate controlling step during the chlorination reaction. However, it could not be the case of resistances with reaction temperature as shown in Figure 5. The effects of product layer diffusion resistance and that of chemical reaction resistance are a trade off in this system. As the reaction temperature increased, the chemical reaction resistance increased and thus the product layer diffusion resistance decreased. 


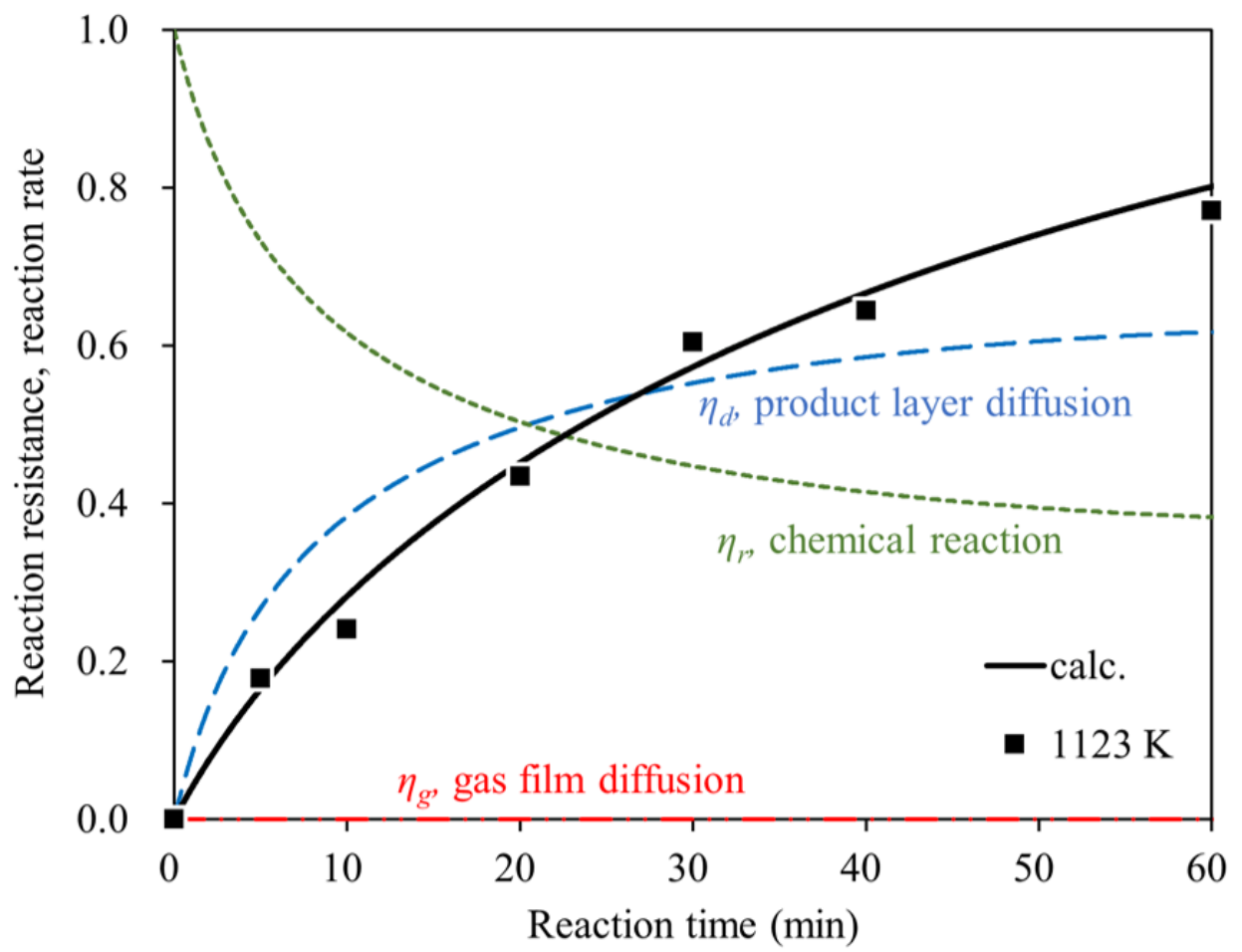

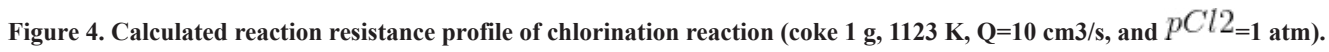




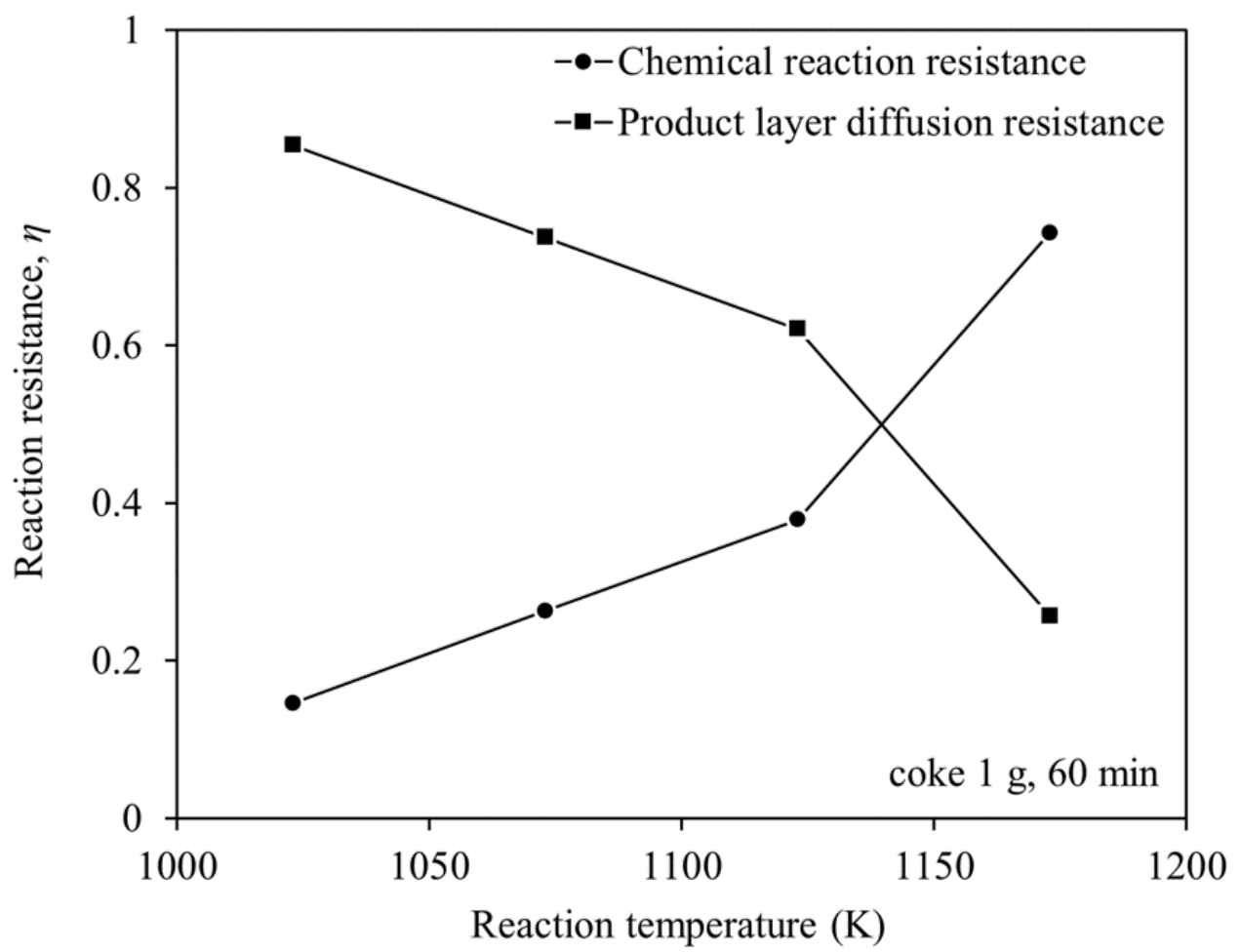

Figure 5. Calculated chemical reaction resistance and product layer diffusion resistance values versus reaction temperature.

In order to clarify this behavior of the variation in resistance with the reaction temperature, the pore size of synthetic rutile was analyzed by utilizing the mercury porosimetry. Figure 6 shows the pore size distributions with different reaction temperature. The average pore size tended to increase with the reaction temperature and the pore size distribution also broaden. 


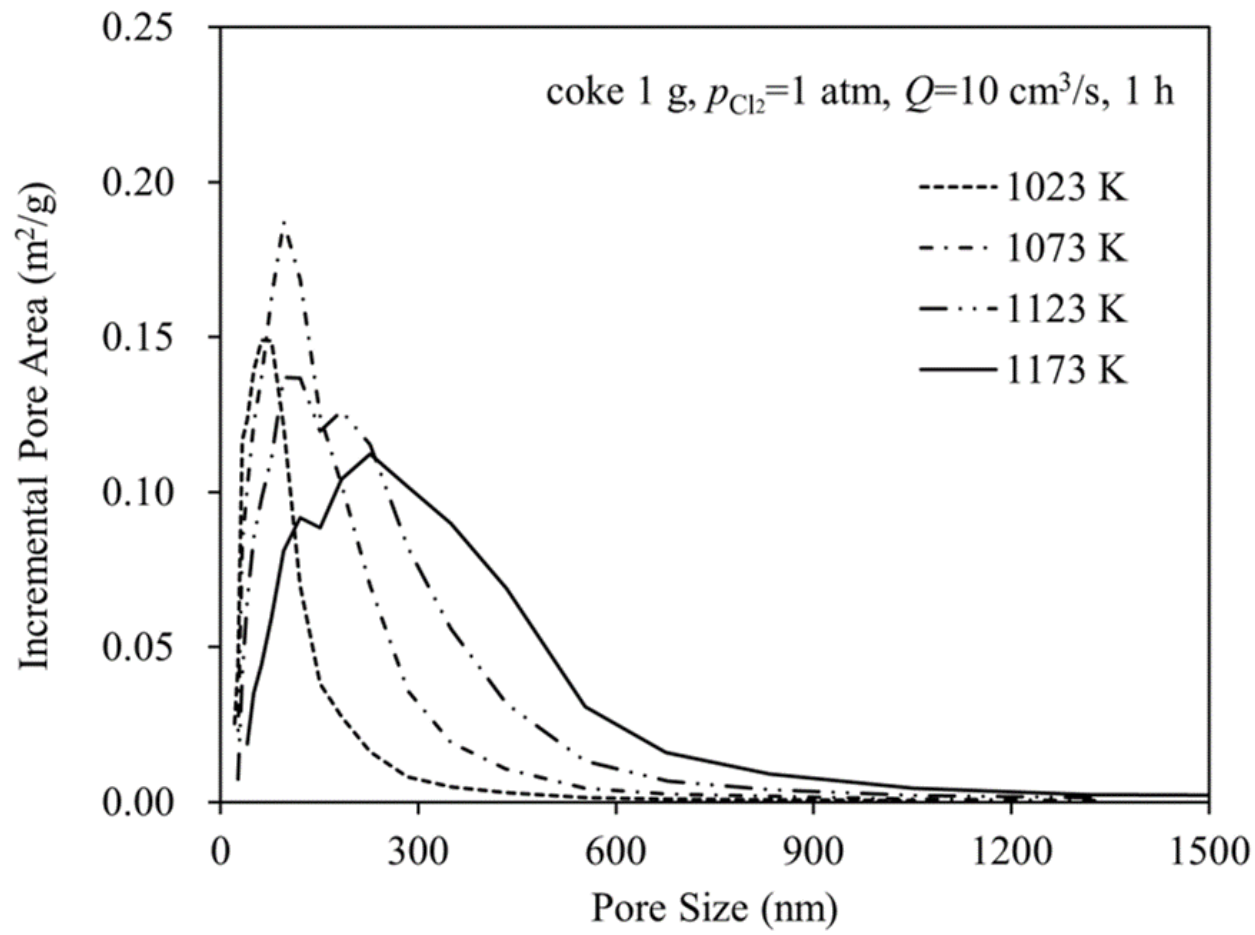

Figure 6. Pore size distribution that chlorinated at different reaction temperatures.

\section{Conclusion}

The selective chlorination of ilmenite concentration with coke and chlorine gas was conducted to study the chlorination reaction kinetics. As the reaction progressed, the cross section images of the produced particle were observed to verify the shrinkage of unreacted core and buildup of product layer. The reaction rate was simulated by applying the formula for the chlorine gas consumption rate of the unreacted core model. The simulated values and the experimental values were in good agreement that the model could be applied in this reaction system.

As the reaction progressed, the rate controlling step changed from chemical reaction control to product layer diffusion control. The diffusion resistance through the product layer was dominant at lower reaction temperature, whereas the chemical reaction resistance became more dominant as the reaction temperature increased. The large pore of the product layer contributed to the diffusion of reactant gas. Consequently, it is believed that the lower diffusion resistance at elevated temperature is due to the large pores of the product layer.

\section{References}

[1] Y. Son, R. Ring, and H.-Sohn, J. of Korean Inst. Of Resources Recycling 25 (2016) 74-81.

[2] T,-S. Yun and Y. Paik, J. Kor. Inst. Met. \& Mater. 14 (1976) 74-80.

[3] G. G. Fouga, D. M. Pasquevich, and A. E. Bohe, Congreso SAM/CONAMET 24 (2007) 230-238.

[4] K. I. Rhee and H. Y. Sohn, Metall. Trans. B, 21B (1990) 341-347.

[5] C. M. Lakshmanan, H. E. Hoelscher, and B. Chennakesavan, Chem. Eng. Sci., 20 (1965) 1107-1113.

[6] S. Yagi and D. Kunii, Symposium on Combustion, 5 (1955) 231-244. 